\title{
Strategi Komodifikasi Budaya dalam Ritual Yaa Qowiyyu pada Masyarakat Jatinom, Klaten
}

\author{
Nur Quma Laila ${ }^{1}$, Saifuddin Zuhri Qudsy ${ }^{2}$ \\ Universitas Gadjah Mada ${ }^{1}$, Universitas Islam Sunan Kalijaga Yogyakarta \\ ${ }^{1}$ nurquma2020@mail.ugm.ac.id, ${ }^{2}$ saifuddin.zuhri@uin-suka.ac.id
}

\author{
Riwayat Jurnal \\ Artikel diterima: 9 Juni 2021 \\ Artikel direvisi: 25 Juni 2021 \\ Artikel disetujui: 25 Juni 2021
}

\section{Kata Kunci: $\quad$ Abstrak}

Komodifikasi Budaya, Ritual, Yaa Qowiyyu, Jatinom

Yaa Qowiyyu sebagai ritual agama tidak lagi bermuatan nilai agama namun juga sarat akan nilai ekonomi-politik. Tulisan ini bertujuan untuk mengetahui bagaimana nilai ekonomi beroperasi di dalam ritual Yaa Qowiyyu dan bagaimana strategi para agensi dalam mempromosikan Yaa Qowiyyu sehingga mendatangkan nilai ekonomi. Dalam artikel ini, data primer dikumpulkan dengan menggunakan metode observasi, wawancara dan dokumentasi sementara data sekunder dikumpulkan melalui studi literatur dengan membaca literatur yang sesuai dengan topik penelitian. Data yang terkumpul kemudian dikategorisasikan dan dianalisis dengan menggunakan teknik deskriptif analisis dengan menggunakan perspektif ekonomi-politik. Hasil penelitian menunjukkan bahwa pengelolaan ritual Yaa Qowiyyu yang berdasarkan pada kebijakan pariwisata berimplikasi luas pada proses komodifikasi budaya. Komodifikasi budaya dalam ritual Yaa Qowiyyu merupakan secondary activity yang mampu menjadi penggerak perekonomian masyarakat

\section{Keyword:}

Commodification of

Cultural,

Rituals,

Yaa Qowiyyu,

Jatinom

\section{Abstract}

Yaa Qowiyyu as a religious ritual not only contains religious values but also full of economic-political values. This paper aims to find out how economic value runs in Yaa Qowiyyu ritual and how the strategies of agencies in promoting Yaa Qowiyyu bring economic value. Primary data in this article was collected by observations, interviews and documentation methods, while secondary data was collected through literature study. Politicaleconomic perspectives are used to analyze the collected data. The results showed that the management of Yaa Qowiyyu ritual which was based on tourism policies had broad implications for the process of cultural commodification. The commodification of 
culture in Yaa Qowiyyu ritual is a secondary activity that is able to encourage the community's economy.

\section{Pendahuluan}

Ritual agama bukan lagi sekadar bermuatan nilai agama, tetapi juga bermuatan politikekonomi. Ritual agama sebagai aset budaya yang dimiliki oleh masyarakat dimanfaatkan sebagai wahana pariwisata sehingga membuka ruang kapitalisasi budaya yang memiliki prinsip nilai tukar uang dan bukan guna. Nilai uang menjadi orientasi baru untuk mendapatkan keuntungan dalam ritual agama sehingga melahirkan bentuk komodifikasi budaya. Komodifikasi budaya, merekonstruksi ritual agama sebagai sebuah atraksi yang dijadikan sumber ekonomi yang kemudian dipertukarkan berdasarkan nilai uang. Dengan demikian, atraksi tidak hanya diminati namun juga mendatangkan sumber ekonomi. Salah satu contoh kasus komodifikasi budaya dalam ritual agama nampak pada tradisi Yaa Qowiyyu sebagai tradisi keagamaan dan budaya yang sudah ada sejak 1688 tahun masehi di Jatinom, Klaten.

Studi yang ada cenderung membahas tradisi ritual Yaa Qowiyyu dalam tiga perspektif. Pertama, tradisi ritual Yaa Qowiyyu dibahas dalam perspektif budaya dimana tradisi Yaa Qowiyyu merupakan tradisi yang menyatukan religi dengan budaya lokal untuk mengingat cikal bakal Jatinom yaitu Ki Ageng Gibrig sebagai tokoh penyebar agama Islam (Basri, 2011; Nur Islami, 2014; Bagas et al., 2017). Kedua, Yaqowiyyu dibahas dalam perspektif agama dimana tardisi ini dapat diterima oleh agama (Islam) sebagai sebuah upacara adat yang tergolong dalam urf sahih atau baik (Amaliyah, 2015; Mubaroq, 2019). Ketiga Yaa Qowiyyu dibahas dalam perspektif pariwisata Yaa Qowiyyu merupakan aset budaya yang digunakan sebagai daya tarik pariwisata Jatinom. Dalam perspektif ini, budaya dikomodifikasikan sebagai sumber ekonomi masyarakat (Yani, 2010; Hamidah, 2009).

Tulisan ini menjadi respon atas kecenderungan studi yang ada dengan mengungkapkan bagaimana Ritual Yaa Qowiyyu yang digunakan sebagai sumber ekonomi dalam instrument pariwisata, memiliki agensi yang berperan dalam mendorong berkembangnya tradisi ritual Yaa Qowiyyu. Dengan mengetahui agensi yang berperan dalam tradisi Yaa Qowiyyu juga sekaligus memperlihatkan relasi kuasa yang terjadi sehingga akan terlihat pihak-pihak yang diuntungkan dalam penyelenggaraan tradisi ritual ini. Sejalan dengan itu, dua pertanyaan dapat dirumuskan: Pertama, bagaimana nilai ekonomi beroperasi di dalam ritual Yaa Qowiyyu? Kedua, bagaimana strategi para agensi dalam mempromosikan Yaa Qowiyyu sehingga mendatangkan 
ekonomi? Dengan demikian dua pertanyaan tersebut menjadi pokok pembahasan dalam tulisan ini.

Tulisan ini didasarkan pada argumen bahwa ekonomi mampu menggerakkan keberlangsungan ritual dengan asumsi bahwa ritual Yaa Qowiyyu bukan lagi domain tokoh adat atau tokoh agama, tetapi telah bergeser pada domain pemerintah dan masyarakat. Komodifikasi digunakan sebagai alat utama untuk mengubah relasi sosial menjadi relasi ekonomi (Curran, 1996). Ritual Yaqowiyu dikemas sebagai bentuk pariwisata yang kemudian digunakan sebagai sumber ekonomi dan secara tidak langsung juga menunjukkan bahwa ritual menjadi ruang terbuka yang mengakomodasi semua orang dengan kepentingannya masingmasing sehingga setiap orang memiliki makna atas ritual itu.

\section{Metode}

Penelitian ini mengambil lokus penelitian di Desa Jatinom, Klaten. Pemilihan lokus didasarkan atas pertimbangan bahwa dalam tradisi Yaa Qowiyyu di Jatinom mekanisme ekonomi dan budaya sangat nampak terlihat terutama pada bazar-bazar dan kegiatan ekonomi lainnya yang mendatangkan keuntungan. Data yang dikumpulkan terdiri dari data primer dan sekunder. Data primer diperoleh melalui observasi, wawancara dan dokumentasi. Observasi dilakukan dengan melihat praktek ritual Yaa Qowiyyu pada masyarakat Jatinom dan wawancara dilakukan kepada pengunjung dan masyarakat setempat. Sementara itu, dokumentasi dilakukan ketika acara perayaan Yaa Qowiyyu dilaksanakan. Data sekunder diperoleh dari studi literatur dengan membaca literatur yang sesuai dengan topik penelitian. Data yang terkumpul kemudian dikategorisasikan sesuai dengan kategori data. Data yang sudah dikategorisasikan kemudian dianalisis menggunakan teknik deskriptif analisis dengan perspektif ekonomi-politik.

\section{Pembahasan}

\section{Komodifikasi Budaya dalam Yaa Qowiyyu}

Yaa Qowiyyu merupakan praktek ritual sinkretisme antara agama dan budaya yang diadakan pada hari Juma'at minggu kedua setiap bulan Sapar dan telah berkembang sejak zaman Mataram Islam. Ritual ini dilakukan untuk mengenang Ki Ageng Gribig sebagai salah satu pendakwah yang menyebarkan ajaran agama Islam di Jatinom, Klaten. Selain itu, ritual ini juga merupakan simbolisasi dari terciptanya ketenangan dan keamanan di dalam masyarakat 
jatinom yang dimanifestasikan dalam bentuk perilaku ngalap berkah. Ngalap berkah ditunjukkan dengan penyebaran kue apem secara massal kepada masyarakat yang hadir dengan menabur kue apem dari tower. Artinya, kue apem yang ditabur tersebut merepresentasikan sebuah berkah yang diterima oleh masyarakat. Seperti tampak pada foto 1 berikut:

Foto 1: Penyebaran apem

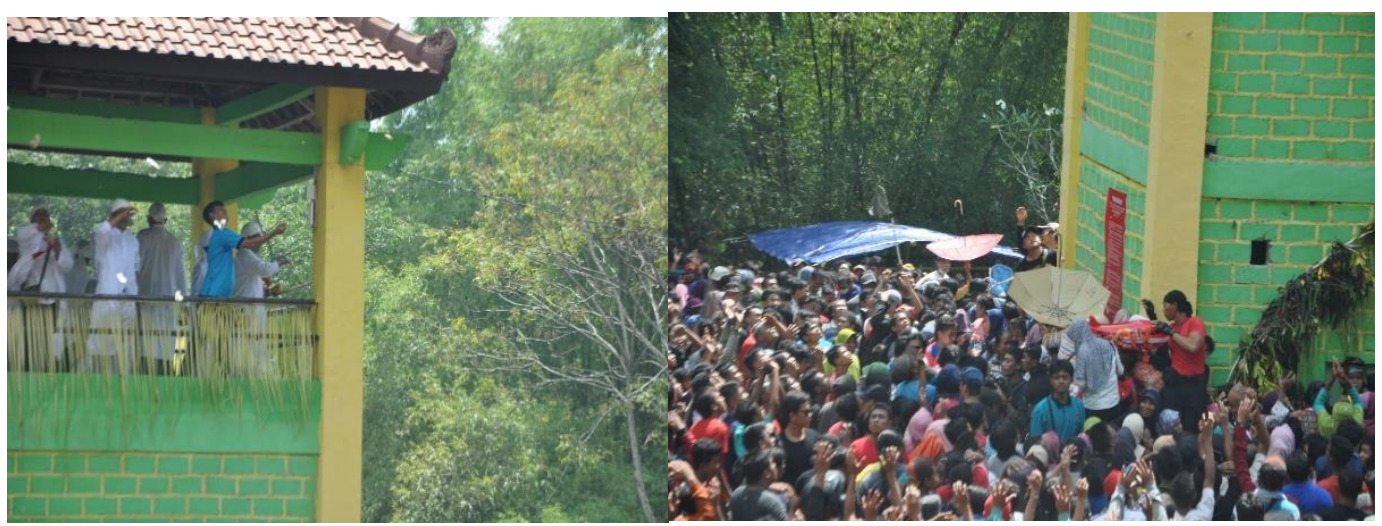

(Sumber: Pribadi, diambil 2016)

Ritual lain yang hadir dengan adanya prosesi ritual Yaa Qowiyyu adalah masyarakat yang datang ke Jatinom bersuci di umbul cilik (sumber mata air) yang berada dibelakang makam Ki Ageng Gibrig. Selain bersuci, masyarakat juga membawa air dari umbul cilik atau meminum langsung air karena dipercaya memiliki berbagai khasiat terutama dipercaya dapat menyebabkan awet muda dan menyembuhkan penyakit. Hal ini sejalan dengan apa yang dikatakan oleh MD (24) yang datang untuk mengikuti ritual Yaa Qowiyyu sebagai berikut:

"Biasalah golek berkah, njaluk berkat. Iki jarene iso gawe awet enom" (Wawancara, 20 November 2020)

Foto 2: Masyarakat meminum dan membawa air dari umbul cilik

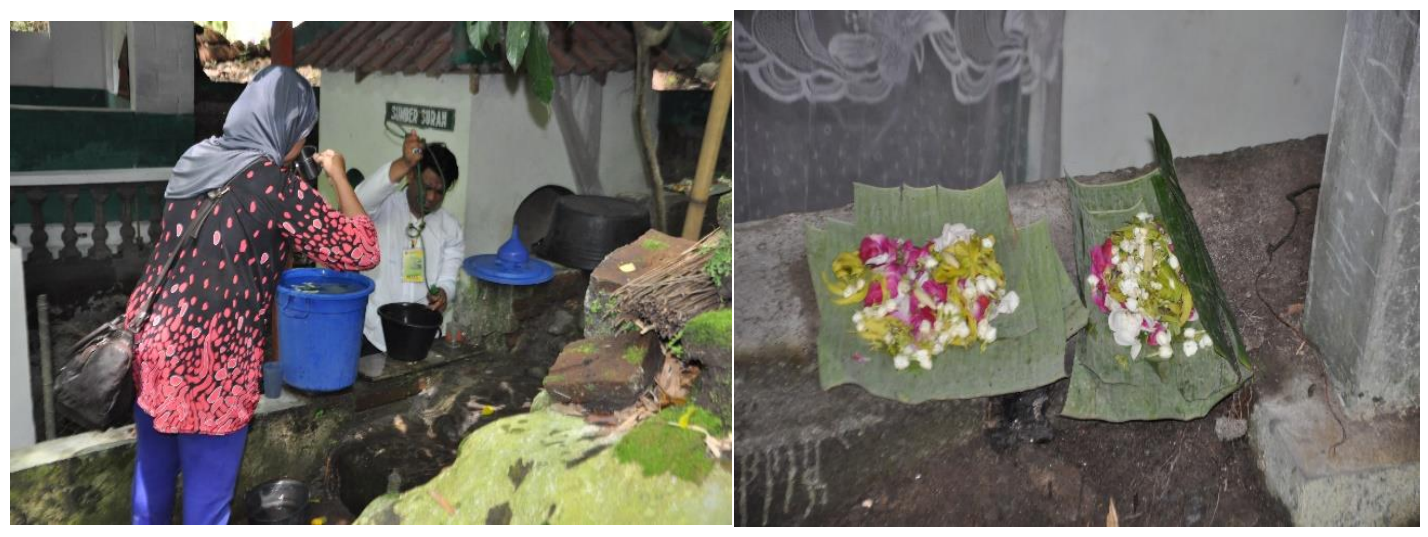

(Sumber: Pribadi, diambil 2016) 
Banyaknya pengunjung yang bersifat musiman memanfaatkan tradisi Yaa Qowiyyu untuk membuka stan-stan dengan menggelar aneka macam barang dagangan dan mendirikan panggung-panggung hiburan. Praktik ini kemudian menunjukkan bahwa telah terjadi secondary activity sebagai aktivitas yang mengikuti primary activity yakni ritual Yaa Qowiyyu. Sekeliling masjid menjadi pasar tiban. Rumah warga dijadikan tempat parkir. Bagi yang tidak membuat apem, bisa membeli apem dari pedagang yang berada disekitar komplek pemakaman Ki Ageng Gibrig.

Foto 3: Stan-stan dan pedagang musiman yang berjualan pada acara Yaa Qowiyyu

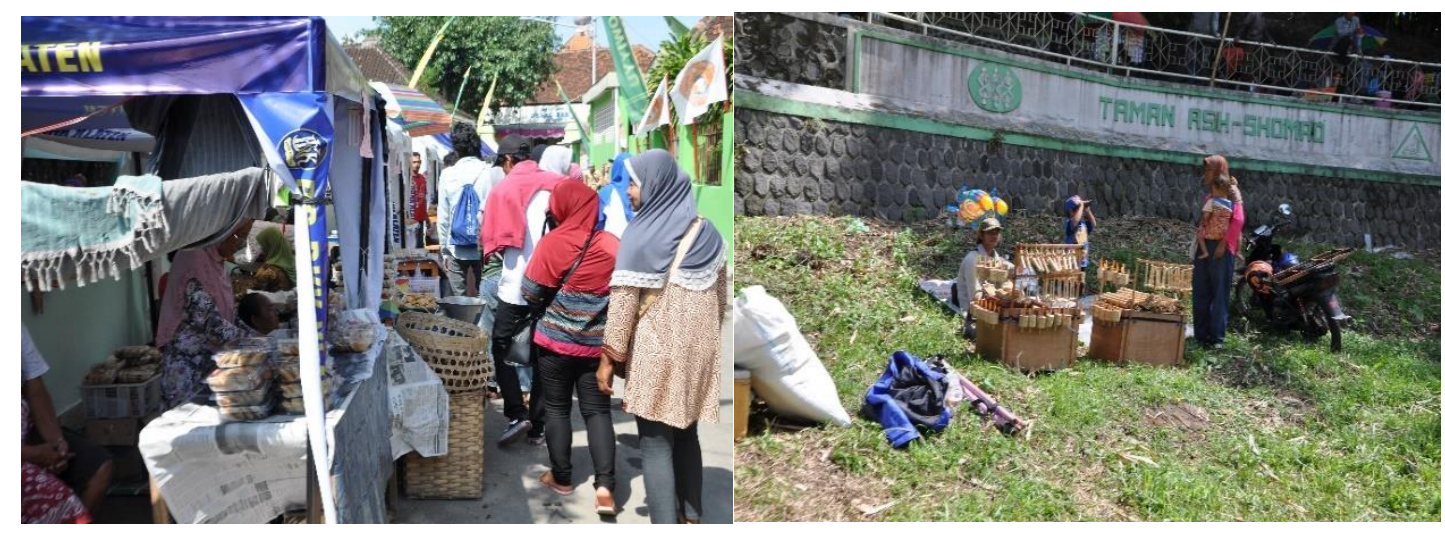

(Sumber: Pribadi, diambil 2016)

Selain itu, warga sekitar Jatinom menyewakan rumah-rumah mereka sebagai homestay untuk menerima ribuan tamu yang akan hadir selama sepekan acara Yaa Qowiyyu. Hal ini seperti yang disampaikan oleh LD (23) sebagai berikut:

"Lek homestay sak retiku yo ono tapi dudu sik bener-bener model homestay tapi yo omah biasa terus disewakne ngono kae. Aku tau reti wong Magetan nyewo soale lek meh nyewo hotel larang tapi embuh piro regone" (Wawancara, 20 November 2020)

Jika mencermati secara mendalam, tampak bahwa pada ritual Yaa Qowiyyu ini tidak saja berlangsungnya ritual agama, maupun budaya. Akan tetapi juga telah berlangsung proses komodifikasi budaya sebagai sumber ekonomi yang mengejawantah dalam bentuk-bentuk komersil (Widyastuti,2011). Komodifikasi budaya pertama nampak pada konsep acara yang merujuk kepada konsep festival sehingga menunjukkan bahwa tradisi Yaa Qowiyyu bukan lagi tradisi yang bersifat sacral namun sudah bergeser ke profan. Hal ini nampak pada penuturan LD (23) sebagai berikut; 
“...Dan konsep acara tahun lalu itu dibuat lebih menarik, ngambil konsep karnaval dadi koyok karnaval jember kae lo lak sing pakai kostum unik-unik gitu. Dan emang di Klaten kan tiap HUT Klaten sendiri selalu ada acara karnaval dengan menampilkan keunikan-keunikan setiap kecamatannya. Nah acara karnaval pas acara Yaa Qowwiyu itu lebih diperjelas lagi" (Wawancara, 20 November 2020)

Banyaknya pengunjung yang datang pada ritual Yaa Qowiyyu kemudian menjadikan ritual ini sebagai obyek pariwisata daerah. Prosesi upacara yang dulunya hanya sebatas ritual telah diselingi dengan berbagai acara kesenian sebagai daya tarik dalam pariwisata. Hal ini menunjukkan telah terjadi transformasi nilai dari sacral ke profan. Dengan demikian, atraksi tidak hanya diminati namun juga mendatangkan sumber ekonomi. Komodifikasi yang dimunculkan tidak jarang terjebak kepada hal-hal penggerusan nilai-nilai yang menghilangkan atau melunturkan dan menjauhkan dengan filosofi dari budaya tersebut berasal (Minawati, 2013). Di sisi lain, komodifikasi budaya mendatangkan dialektika ruang sakral ke profan. Pada tradisi ini, praktik dan simbol budaya dibungkus dengan kepentingan ekonomi-politik dimana tourism digunakan sebagai instrumen dalam mekanisme pasar. Hal ini kemudian merubah acara ritual Yaa Qowiyyu. Perubahan nampak dimana sebelum acara dikelola oleh pemerintah, masyarakat yang ingin masuk tidak dipungut biaya, hanya mengisi kotak pembangunan sekedarnya. Namun sekarang setiap pengunjung yang datang dipungut biaya dengan membeli karcis yang tersedia di loket sebelum pintu masuk. Hal ini kemudian menggambarkan bahwa komodifikasi budaya dapat dimaknai sebagai komersialisasi (memperdagangkan) simbol-simbol budaya menjadi sesuatu yang dapat diperjualbelikan untuk mendapatkan untung (Rozaki, 2013).

Selanjutnya pada puncak tradisi Yaa Qowiyyu ditutup dengan menyebarkan kue apem yang berada di komplek pemakaman Ki Ageng Gibrig untuk diperebutkan oleh masyarakat. Kue apem ini bisa menjadi tumbal, tolak bala, atau syarat untuk berbagai tujuan. Penyebaran dilakukan selesai Shalat Jumat dengan membawa gunungan apem yang diarak oleh paraga penyebaran ke bangsal makam Kyai Ageng Gribig terlebih dahulu dan kemudian gunungan dibawa ke panggung kehormatan untuk disebar.

\section{Strategi dalam Mempromosikan Yaa Qowiyyu}

Pada awalnya upacara tradisi ini hanya terbatas untuk kerabat Ki Ageng Gibrik dan masyarakat sekitar Jatinom. Namun antusias masyarakat yang datang setiap tahun dari berbagai daerah semakin banyak sehingga tradisi Yaqowiyu saat ini telah melibatkan beberapa unsur masyarakat dan instansi pemerintah yang terkait. Sejak dikeluarkannya Surat Keputusan Bupati Kepala Daerah Tingkat II Klaten mengenai pembentukan panitia perayaan Yaa 
Qowiyyu tahun 1986 di Jatinom, penanganan Yaa Qowiyyu dilakukan oleh Pemerintah Daerah yang diserahkan kepada Dinas Pariwisata. Hal ini kemudian nampak bahwa agensi utama dalam pelaksanaan acara Yaa Qowiyyu adalah negara yang direpresentasikan oleh Dinas Pariwisata dan pemerintah desa.

Dalam pelaksanaan Yaa Qowiyyu yang digelar selama satu minggu, sejumlah agenda baru sebagai strategi untuk menarik pengunjung. Berbagai acara digelar seperti pentas kesenian, jemparingan (lomba panah tradisional) yang dilakukan oleh Yayasan Ash-Shomad, lomba pembuatan apem, lomba memancing, bazar makanan dan jajanan, pameran dan pelatihan fotografi Jatinom oleh wangsul jatinom, dan pentas wayang kulit. Acara-acara ini didukung oleh berbagai elemen seperti insitusi sekolah dimana para siswa diajak untuk memeriahkan acara lewat pagelaran kesenian. Seperti yang diungkapkan oleh LD (23) sebagai berikut:

"Acara Yaa Qowiyyu dibuat konsep lebih menarik supaya orang itu tahu jatinom itu sendiri sih lak terus acara ini kan berupa rangkaian acara. Nah ini juga akhirnya banyak kerjasama dengan sekolahsekolah agar mewakili untuk event ini. Jadi bentuk e koyok drumband, tari-tarian cah cilik ngono kae. Koyomen kabeh melu andil lak, kan mayan to memanfaatkan hahaha" (Wawancara, 20 November 2020)

Selain berbagai kegiatan kesenian dan parade nusantara yang menampilkan para seniman muda dari berbagai daerah dalam sepanjang rangkaian Yaa Qowiyyu, diskusi warisan dan niai-nilai Kyai Ageng Gibrig juga dilakukan oleh Ki Hadjar Poerwatjarita sebagai daya tarik dalam memeriahkan rangkaian acara Yaa Qowiyyu. Berbagai agenda baru yang digunakan sebagai daya tarik pariwisata tersebut sekaligus memperlihatkan kembali transformasi nilai dari sacral ke profan. Selain itu nampak bahwa pengembangan kesenian seperti jemparingan yang merupakan panahan tradisional sejak zaman Mataram dimunculkan kembali sebagai pengembangan dari kapasitas pariwisata.

Selain menciptakan berbagai acara sebagai bagian dari rangkaian acara Yaa Qowiyyu, strategi dalam menarik pengunjung juga dilakukan dengan mempromosikan acara Yaa Qowiyyu dalam berbagai media, baik cetak maupun online. Promosi gencar dilakukan melalui social media yakni pada Instagram dan twitter. Pada platform Instagram nampak pada hastag (\#) yang digunakan untuk mengenalkan berbagai rangkaian acara yang dilakukan. Selain hastag (\#) terdapat akun resmi acara Yaa Qowiyyu sebagai sumber informasi dan dokumentasi acara yakni@Tirtajatinom. Selain akun resmi tersebut, acara Yaa Qowiyyu bekerjasama 
dengan berbagai media untuk mempromosikan acara seperti yang dikatakan oleh LD (23) sebagai berikut:

"Pengelolaan e kui akeh kerjasama dengan berbagai pihak. Salah satune wangsul jatinom. Lek event organizer aku ra ngerti lek kui tapi paling ketara iku disokong karo dinas pariwisata" (Wawancara, 20 November 2020)

Berdasarkan wawancara dan observasi yang telah dilakukan terdapat banyak akun Instagram yang ikut serta dalam mempromosikan acara Yaa Qowiyyu seperti @wangsuljatinom, @ solothok,dan@dolandewewani.

Foto 4: Media Promosi Online Acara Yaa Qowiyyu

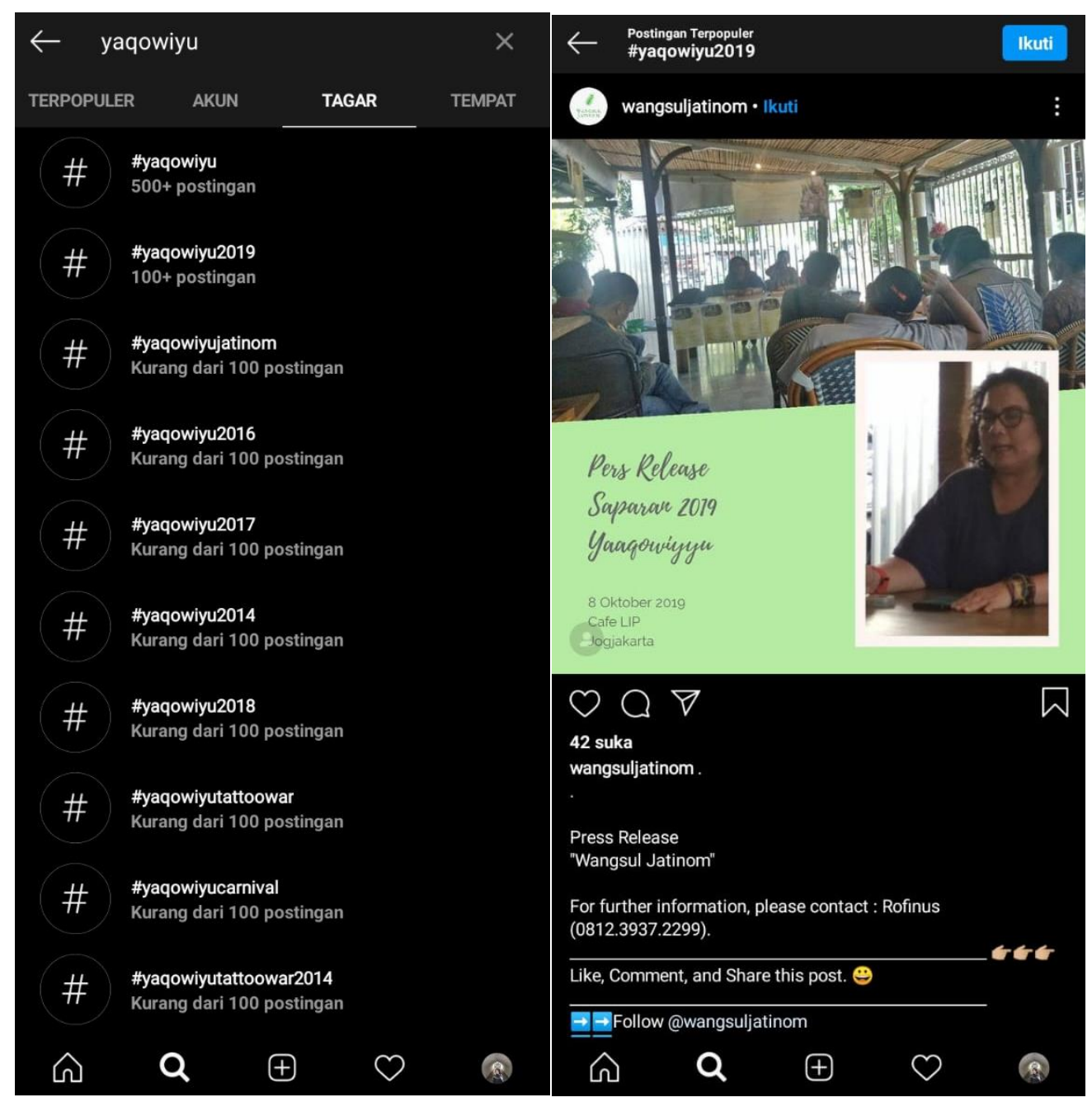

(Sumber: Pribadi diambil 2020)

Kemudian promosi juga dilakukan pada media cetak dimana dinas pariwisata bekerjasama dengan kabar klaten sebagai salah satu media cetak yang banyak digemari oleh masyarakat Klaten. Hal ini disampaikan oleh LD (23) sebagai berikut: 
"Nyatu promosine gencar banget lak mulai tahun lalu soale antusias asyarakat dating ke Jatinom buat acara itu kan besar. Setahuku lek media social enek tirta jatinom ning Instagram terus enek kerjasama dengan kabarklaten. Kabarklaten kan media yang paling banyak diikuti masyarakat Klaten"(Wawancara, 20 November 2020)

Berbagai exposure yang ada diatas mengenai berbagai strategi yang dilakukan dalam mempromosikan acara Yaa Qowiyyu guna mendapatkan keuntungan ekonomi (komodifikasi) telah memperlihatkan bahwa ritual yang pada sejarahnya dianggap sebagai sesuatu yang sacral telah bertransformasi secara nilai (profan).

\section{Simpulan}

Ritual Yaa Qowiyyu dikemas sebagai bentuk pariwisata yang digunakan sebagai sumber ekonomi masyarakat. Pengelolaan ritual tradisi yang berdasarkan pada kebijakan pariwisata berimplikasi luas pada proses komodifikasi budaya. Komodifikasi budaya dalam ritual Yaa Qowiyyu merupakan secondary activity yang mampu menjadi penggerak perekonomian masyarakat. Selain itu, ritual Yaa Qowiyyu secara tidak langsung juga menunjukkan bahwa ritual menjadi ruang terbuka yang mengakomodasi semua orang dengan kepentingannya masing-masing sehingga setiap orang memiliki makna atas ritual itu. Tulisan ini terbatas pada kajian mengenai Yaa Qowiyyu dari sudut pandang budaya dan ekonomi. Kajian lainnya pada dasarnya dapat dilihat pada fenomena Yaa Qowiyyu dalam hubungan antara agama dengan budaya lokal masyarakat Klaten. Oleh karena itu, dibutuhkan kajian lanjutan yang melihat hubungan agama dengan budaya lokal dalam tradisi Yaa Qowiyyu sehingga akan melahirkan penelitian yang lebih komprehensif.

\section{Daftar Pustaka}

Amaliyah, E. I. (2015). Relasi Agama dan Budaya Lokal: Upacara Yaqowiyyu Masyarakat Jatinom Klaten. Fikrah.

Aprianto, N. E. K. (2018). Kemiskinan Dalam Perspektif Ekonomi Politik Islam. Islamiconomic: Jurnal Ekonomi Islam. https://doi.org/10.32678/ijei.v8i2.60

Bagas, Y., Suwandi, A. S., \& Widodo, S. T. (2017). Yaqowiyyu Tradition In Klaten: Analysis Of Function. 1965, 542-547.

Basri, M. H. (2011). Ritual Ya Qowiyu: Pergulatan Makna Modernitas, Agama, Budaya Lokal dan 
https://doi.org/10.18860/el.v0i0.426

Capitanio, J. (2020). Ritual and Self-Cultivation in the Daoist Practice of "oblatory Refinement.” Numen. https://doi.org/10.1163/15685276-12341556

Caporaso, J. A., \& Levine, D. P. (1992). Theories of Political Economy. In Theories of Political Economy. https://doi.org/10.1017/cbo9780511840197

Demmrich, S., \& Wolfradt, U. (2018). Personal rituals in adolescence: Their role in emotion regulation and identity formation. Journal of Empirical Theology. https://doi.org/10.1163/15709256-12341373

Frishkopf, M. (2018). Paralinguistic Ramification of Language Performance in Islamic Ritual. Yale Journal of Music \& Religion. https://doi.org/10.17132/2377-231x.1099

Hamidah, A. (2009). Motivasi Pengunjung Upacara Yaqawiyyu Di Jatinom Kabupaten Klaten Tahun 2008 (Doctoral dissertation, Univversitas Muhammadiyah Surakarta)

Irianto, A. M. (2016). Komodifikasi Budaya Di Era Ekonomi Global Terhadap Kearifan Lokal: Studi Kasus Eksistensi Industri Pariwisata dan Kesenian Tradisional di Jawa Tengah. Jurnal Theologia. https://doi.org/10.21580/teo.2016.27.1.935

Johnson, L. E., Caporaso, J. A., \& Levine, D. P. (1994). Theories of Political Economy. Southern Economic Journal. https://doi.org/10.2307/1060455

Minawati, R. (2013). Komodifikasi: Manipulasi Budaya Dalam (Ajang) Pariwisata. Jurnal Ekspresi Seni.

Mubaroq, H. H. (2019). Interaksi antara Gerakan Sosial modernisme Muhammadiyah dengan Kegiatan Tradisional Yaqowiyyu di Jatinom. JUSPI (Jurnal Sejarah Peradaban Islam). https://doi.org/10.30829/juspi.v3i1.4076

Mudana, I. W., \& Ribek, P. K. (2017). Komodifikasi Seni Lukis Wayang Kamasan Sebagai Produk Industri Kreatif Penunjang Pariwisata. Jurnal Seni Budaya.

Niko, N., \& Atem, A. (2019). Festival Air (Songkran): Komodifikasi Budaya di Thailand. Simulacra: Jurnal Sosiologi. https://doi.org/10.21107/sml.v2i1.5518

Nur Islami, M. E. (2014). Simbol Dan Makna Ritual Yaqowiyu Di Jatinom Klaten. Media Wisata.

Negilski, M. (2015). Constructing A Contemporary Dance Ritual (Doctoral dissertation, UC Santa Cruz).

Pollok, A. (2014). The power of rituals: Mendelssohn and Cassirer on the religious dimension of Bildung. Religious Studies. https://doi.org/10.1017/S0034412514000031

Purzycki, B. G., \& Sosis, R. (2013). The extended religious phenotype and the adaptive coupling of ritual and belief. Israel Journal of Ecology and Evolution. https://doi.org/10.1080/15659801.2013.825433

Roelofse, C. (2014). Ritual and muthi murders: An Afro-ethno-criminological assessment of the phenomenon and development of a new typology. Acta Criminologica: Southern African Journal of Criminology, 2014(1), 71-83.

Rozaki, A. (2013). Komodifikasi Islam (Kesalehan dan Pergulatan Identitas di Ruang Publik). Jurnal Dakwah, XIV(2), 199-212. 
Widyastuti, D. A. R. (2011). Komodifikasi Upacara Religi Dalam Pemasaran Pariwisata. Jurnal ASPIKOM. https://doi.org/10.24329/aspikom.v1i2.18

$\mathrm{Wu}, \mathrm{Q}$. (2018). The structure of ritual and the epistemological approach to ritual study. Journal of Chinese Sociology. https://doi.org/10.1186/s40711-018-0081-x

Yani, Y. Y. I. (2010). Manajemen objek dan daya tarik wisata upacara tradisional Yaqowiyu di kecamatan Jatinom kabupaten Klaten.

Zamzamy, A. (2016). Kapitalisasi Agama pada Tayangan Televisi (Tinjauan Teori Ekonomi Politik Media). Oeconomicus Journal of Economics, 1(1), 49-70. 